\title{
Sleep and breathing in premature infants at 6 months post-natal age
}

\author{
Yu-Shu Huang ${ }^{1}$, Teresa Paiva², Jen-Fu Hsu ${ }^{3}$, Ming-Chun Kuo ${ }^{1}$ and Christian Guilleminaultt ${ }^{*}$
}

\begin{abstract}
Background: Poor sleep contributes to the developmental problems seen in preterm infants. We evaluated sleep problems in preterm infants 6 months of post-gestational age using the subjective Brief Infant Sleep Questionnaire (BISQ) and objective sleep tests. We also compared the sleep of premature infants with that of full-term infants.

Methods: The study included 68 6-month-old full-term healthy infants and 191 premature infants born at <37 weeks gestation. All parents completed the BISQ-Chinese version and sleep diaries. At the same time, all premature infants were submitted to one night of polysomnography (PSG) in the sleep laboratory and also were set up with an actigraph kept for 7 days. Statistical analyses were performed using correlation coefficients and the t-test with SPSS version 18 to compare questionnaire responses with other subjective and objective measures of sleep.

Results: The sleep problems indicated in the subjective questionnaire for the premature infants, particularly: "the nocturnal sleep duration, number of night awakenings, daytime sleep duration, duration of time with mouth breathing, and loud-noisy breathing" had significant correlations with sleep diaries, actigraphy and PSG results. The BISQ showed that duration of infant's sleeping on one side, nocturnal sleep duration, being held to fall asleep, number of nighttime awakenings, daytime sleep duration, subjective consideration of sleep problems, loud-noisy breathing, and duration spent crying during the night were significantly different between the premature infants and the term infants. PSG confirmed the presence of a very high percentage (80.6\%) of premature infants with $A H I>1$ event/hour as indicated by the questionnaire.
\end{abstract}

Conclusion: Premature infants have more sleep problems than full-term infants, including the known risk of abnormal breathing during sleep, which has been well demonstrated already with the BISQ-Chinese (CBISQ).

Keywords: Sleep questionnaire, Sleep-disordered breathing, Prematurity, Full-term infant

\section{Background}

Sleep is essential to human life and developmentally involves both physiologic and mental processes. During infancy, humans spend a majority of time in sleep [1-4]. Sleep is recognized not only as a resting state, but also as a state of intense brain development during which neurotransmitters specific for each sleep stage impact brain maturation [2,5-7].

Numerous studies have shown differences in sleep quality between premature and full-term infants [3-6,8-12]. Premature infants often have many problems during sleep, and the more premature they are the more problems are

\footnotetext{
* Correspondence: cguil@stanford.edu

${ }^{4}$ Stanford University Sleep Medicine Division, 450 Broadway Street, MC 5704, Redwood City CA 94063, Stanford, USA

Full list of author information is available at the end of the article
}

seen $[6,8]$. However, when sent home, the infant is considered by the pediatrician to have passed any life-threatening situations. Also, it seems that premature infants develop sleep-wake cycles differently from full-term infants, but that maturation of sleep is related to both time since birth and gestational age $[9,12]$. Many maturational events occur during sleep. Some parental reports indicated that $21 \%$ of children born prematurely are habitual snorers [13-15]. Premature infants have the well-known risk of abnormal control of breathing during sleep just after birth, and sleep apnea of prematurity has been well described [13-15]. Their presence usually leads premature infants to stay in the hospital setting till judged to have normal control of breathing during sleep. Many functions are altered in premature infants, and more so the more premature 
the infant is. Often there is generalized hypotonia, well known by specific neurological exams including regular follow-up of the presence of the "scarf-sign" [16], but there is also immaturity of many functions, including poor sucking and poor swallowing, and often lack of coordination of sucking, swallowing and breathing, leading to important and well documented oxygen saturation drops during feeding when such dysfunctions exist $[17,18]$. The sleep breathing problems also may be due to a lack of tone in the upper airway followed by collapse and obstruction or diaphragmatic movement dysfunction with immaturity of reflexes. Therefore, sleep-disordered breathing (SDB) is often noted in premature infants $[14,15]$. In the recent past, we made the preliminary observation that premature infants may have oral-facial developmental growth problems [18]. Such difficulties may lead to specific breathing problems during sleep and impair the sleep of the infants.

Our study focuses on the sleep of premature infants at 6 months of post-natal age who were born between 24 and 36 weeks of gestational age but had been considered to be in sufficient good health to be sent home without any treatment, and who were having only regular postnatal visits scheduled with the pediatrician. We compared our findings to those simultaneously obtained in a small group of full-term infants born during the same period.

\section{Methods}

\section{Subjects}

During the years 2010-2012, women delivering before 37 weeks of gestational age were asked to enroll their neonates prior to discharge from the neonatal intensive care unit of Chang Gung Memorial Hospital, a medical center with a pediatric department in Taiwan as part of the preterm infant group. Both boys and girls were included. The full-term infant group, with a gestational age ranging from 37 to 40 weeks and birth body weight of more than 2500 grams, was enrolled from the neonatal outpatient clinic in our hospital.

\section{Inclusion criteria}

- All neonates born in our hospital before 37 completed gestational weeks, without presentation of exclusion criteria and with a signed parental consent form during the study period comprised the "preterm-infants group".

- All neonates delivered at 37 to 40 weeks of gestational age with birth body weight of more than 2500 grams, without presentation of exclusion criteria and with a signed parental consent form during the study period comprised the "full-term-infants group".

\section{Exclusion criteria}

- Neonates with severe physical impairments (such as severe congenital heart diseases, DiGeorge syndrome, congenital hydrocephalus, and kernicterus) due to perinatal insults or hypoxic ischemic encephalopathy. We also excluded bronchopulmonary dysplasia or still required oxygen support (nasal cannula) after discharge.

- Neonates with confirmed severe congenital malformations.

\section{Methods}

(1) After obtaining written parental informed consent to take part in an institutionally approved human subject protocol (Chang Gung Memorial Hospital IRB: 98-2670C), the infants meeting the inclusion criteria began participation in our prospective growth study during the first year of life.

(2) Infants had a pediatric evaluation at a regular 6-month post-natal visit and a sleep clinical evaluation. As part of this sleep evaluation, all premature infants underwent one night of PSG (Embla N7000 PSG recording-sleep- system) in the pediatric sleep laboratory. The following variables were monitored: electroencephalography, electromyography, electrocardiography and electro-oculography. Respiration was monitored with a nasal-cannulapressure transducer, oral thermistor, thoracic and abdominal inductive plethysmography bands and pulse-oximetry. The infants were continuously video-monitored. For PSG scoring, the recommendations of the AASM-2007 were followed [7].

(3) All infants were set up with an actigraph (Philips Respironics actiwatch 2, with a small size well-suited for use with younger subjects or those sensitive to wrist-worn devices.) on the left leg of the non-dominant side. The equipment measured body movements and light exposure. It was placed on the infant at the time of the visit and kept for 7 days, and was analyzed with commercially available software with one point every 2 minutes and indicated activity/non-activity. The equipment was correlated with a log simultaneously kept by care-givers.

(4) At the same time, the parents were asked to fill out a validated questionnaire, the "Brief Infant Sleep Questionnaire-Chinese version", (CBISQ), at the regular 6-month and 7-month visits to check the consistency of responses. The CBISQ is derived from the Brief Infant Sleep Questionnaire (BISQ) [19] of Avi Sadeh Additional file 1. The original BISQ had 13 items distributed in 3 categories, evaluating sleep duration, night awakenings, and method of falling 
asleep of infants aged 29 months or younger. To validate the Chinese version of the BISQ, we first translated and then back-translated the BISQ from English to Chinese. The test-retest reliability of the CBISQ was acceptable. There was significant correlation between the repeated sleep measures for location of sleep $\left(r=0.678^{*}\right)$, preferred body position $\left(r=0.796^{*}\right)$, nocturnal sleep duration $\left(r=0.534^{*}\right)$, method of falling asleep $\left(r=0.848^{*}\right)$, difficulty in falling asleep $\left(r=0.785^{*}\right)$, number of night awakenings $\left(\mathrm{r}=0.439^{*}\right)$, daytime sleep duration $\left(\mathrm{r}=0.455^{*}\right)$, and subjective consideration of sleep problems $\left(r=0.663^{*}\right)$. In order to evaluate respiratory sleep problems compared with actigraphy and PSG, we added 3 questions to the BISQ to create the CBSIQ version; these included "time spent with mouth breathing" $\left(r=0.568^{*}\right)$, "severity of loud-noisy breathing" $(0.760 *)$, and "time spent crying during the night" $(\mathrm{r}=0.206)$.

(5) The small group $(n=68)$ of full-term infants (the "controls") whose parents signed the consent form underwent a similar evaluation and was studied the same way as the premature infants.

\section{Analysis}

Pediatrician notes of the 6-month follow-up evaluation for both the premature and full-term infants were reviewed. Complaints with specific emphasis on sleep were collected. The responses to the CBSIQ were then tabulated. Responses of premature infants one month later to the same questionnaire were also tabulated, and actigraphy and PSG data were analyzed. The statistical software package SPSS, Version 18 was used for data analysis. Variables are presented as either mean \pm standard deviation (SD) or frequency. We used the t-test and Chi-square test for evaluation of differences between these 2 groups. The Pearson correlation coefficient was used in analysis of correlation between questionnaire and sleep Lab data. The statistical significance was defined at the 0.05 level.

\section{Results}

\section{Demographic data}

We originally signed up 229 premature infants from the PICU, but only 191 (83.41\%) completed the study when they were 6 months old. The 1916 -month-old premature infants in the preterm infants group comprised 99 boys and 92 girls with an average birth body weight of $1646.66 \mathrm{~g}$. The average gestational age was 31.52 weeks, with a maximum of 36 weeks and minimum of 24 weeks. There were 68 6-month-old infants in the full-term infants group, including 34 boys and 34 girls with an average birth body weight of 3169.69 grams and average gestational age of 38.35 weeks (Table 1 ).

\section{The subjective and objective sleep problems of the premature infants (Table 2)}

We compared the subjective CBISQ to other objective data obtained from sleep diaries, actigraphy and PSG data. These items of CBISQ showed sleep measures of "nocturnal sleep duration, number of night awakenings, daytime sleep duration and loud-noisy breathing" were significantly correlated with sleep diary, actigraphy and PSG. Items such as "mouth breathing" and "loud-noisy breathing" correlated with "total number of obstructive apnea during sleep" in PSG. Longer "Daytime sleep duration" also correlated with $\mathrm{AHI}>1$; We were interested in these correlations as "mouth breathing" and "Loud-noisy breathing" are common symptoms associated with pediatric obstructive sleep apnea. Moreover, higher AHI means severe OSA will interrupt sleep and increase night awakenings and then induce daytime sleepiness. Therefore, the trend in the correlation between "AHI" and "number of obstructive apnea" in PSG and "Daytime sleep duration" in CBISQ were important and meaningful. The additional questions in the CBISQ pertaining to respiratory sleep problems also were shown to correlate with PSG.

The PSG data showed that $80.6 \%$ of 6 -month-old premature infants had an apnea-hypopnea index (AHI) $>1$ event/ hour (mean $\mathrm{AHI}=3.63 \pm 3.24$ ), mean $\mathrm{SaO} 297.01 \pm 1.00 \%$, total sleep time $368.83 \pm 55.05$ mins, sleep efficiency $82.43 \pm 14.66 \%$, and REM $24.03 \pm 6.43 \%$ at polysomnography.

\section{Comparison of the differences between full-term and premature infants (Table 3)}

Since our CBISQ was shown to be a reliable and valid tool for sleep measurement, we used the data to compare the differences in sleep between the preterm-infant and

Table 1 Demographic data of the study subjects

\begin{tabular}{lllll}
\hline & & Preterm infants $(\mathbf{n}=\mathbf{1 9 1})$ & Full-term infants $(\mathbf{n}=\mathbf{6 8})$ & P value \\
\hline Gender & Male & $\mathrm{n}=99(51.83 \%)$ & $\mathrm{n}=34(50 \%)$ & $\mathrm{n}=34(50 \%)$ \\
& Female & $\mathrm{n}=92(48.17 \%)$ & $3169.69 \pm 410.58$ & $<0.001^{*}$ \\
Birth body weight $(\mathrm{g})$ & & $1646.66 \pm 588.60$ & $49.61 \pm 1.88$ & $<0.001^{*}$ \\
Birth body height $(\mathrm{cm})$ & $39.96 \pm 5.11$ & $34.25 \pm 1.24$ & $<0.001^{*}$ \\
Head circumference (cm) & $28.88 \pm 3.33$ & $38.35 \pm 1.43$ & $<0.001^{*}$ \\
Gestational age (weeks) & $31.52 \pm 3.21$ & &
\end{tabular}

Birth body weight, Birth body height and Head circumference were all assessed at birth. 
Table 2 Subjective and objective sleep problems of premature infants

\begin{tabular}{|c|c|c|c|}
\hline Questionnaire & Objective sleep measure & $r$ & $P$ value \\
\hline CBISQ & Criterion of sleep diary & 0.757 & $0.011^{*}$ \\
\hline Nocturnal sleep duration & Nocturnal sleep duration & & \\
\hline \multirow[t]{3}{*}{ Number of night awakenings } & Nocturnal awake time & 0.632 & $0.002^{*}$ \\
\hline & Numbers of night awakening & 0.580 & $0.001^{*}$ \\
\hline & Nocturnal sleep efficiency & -0.644 & $<0.001^{*}$ \\
\hline Daytime sleep duration & Daytime sleep duration & 0.630 & $0.002^{*}$ \\
\hline Loud-noisy breathing & Daytime sleep duration & 0.348 & $0.064^{+}$ \\
\hline CBISQ & Actigraphy criterion & & \\
\hline \multirow[t]{2}{*}{ Time spent with mouth breathing } & Awakening time during sleep & 0.514 & $0.042^{*}$ \\
\hline & Nocturnal sleep efficiency & -0.255 & $0.013^{*}$ \\
\hline CBISQ & PSG criteria & & \\
\hline Nocturnal sleep duration & Nocturnal sleep duration & 0.545 & $0.002^{*}$ \\
\hline Number of night awakenings & Desaturation index & 0.636 & $0.003^{*}$ \\
\hline \multirow[t]{2}{*}{ Daytime sleep duration } & AHI in sleep & 0.767 & $0.075^{+}$ \\
\hline & Awakening after sleep onset & 0.350 & $0.080^{+}$ \\
\hline Time spent with mouth breathing & Obstructive apnea count & 0.509 & $0.026^{*}$ \\
\hline \multirow[t]{2}{*}{ Loud-noisy breathing } & Arousal count & 0.401 & $0.089^{+}$ \\
\hline & Obstructive apnea count & 0.535 & $0.018^{*}$ \\
\hline
\end{tabular}

*P value $<0.05{ }^{+} \mathrm{P}$ value $<0.10$.

AHI: Apnea-Hypopnea Index (events/hour); Desaturation index: desaturation events/hour; "Arousal count" means total number of arousal during sleep; "Obstructive apnea count" means total number of obstructive apnea during sleep.

full-term-infant groups. The results revealed, as expected, a significant difference between the 2 groups: The premature group preferred a side body position and being held when falling asleep, had more night awakenings, greater subjective mention of presence of a sleep problem by caregivers, louder noisy breathing and more time spent crying during the night. Also, the premature infants had longer nocturnal and daytime sleep duration.

\section{Discussion}

Based on the results described above, we consider the CBISQ a reliable and valid tool for the measurement of sleep problems in infants. It can be used to measure nocturnal sleep duration, number of night awakenings, daytime sleep duration, time spent breathing with the mouth and loud-noisy breathing during sleep. These measures may indicate the presence of underlying infancy sleep problems and sleep-disordered-breathing. Finally, to make the CBISQ an internationally available tool, it was submitted to a Chinese-English back-translation.

Not only did our study validate the CBISQ, but it is also the first study targeting the difference between premature and full-term infants through a reliable and valid screening questionnaire. Based on our results, premature infants, rather than full-term infants, preferred a side body position and being held when falling asleep. Apart from this, premature infants had longer nocturnal sleep duration, more night awakenings, and longer daytime sleep duration. The caregivers of premature infants noted that their children had more sleep problems. A significant difference between preterm and full-term infants in nocturnal sleep duration and loud-noisy breathing was noted. The number of night awakenings and time spent with mouth-breathing also varied between the 2 groups. These questionnaire findings indicated a higher prevalence of sleep-breathing disorders [20-22], and correlated with those obtained with PSG that showed a very high percentage $(80.6 \%)$ of premature infants with AHI greater than 1 event/hour. These disorders then impact nocturnal sleep time and quality.

As a pilot study in this field, our results provide new insights into the difference between premature and fullterm infants with regard to sleep problems. During the first year of life, infancy-sleep is a rapid maturational process $[23,24]$, so the settling time, daytime sleep duration and time spent crying during the night may vary widely between repeated questionnaires. Infancy sleep maturation may impact the maturation of the central nervous system, overall functioning, and future cognitive, motor, and temperament development [25].

There are some methodological limitations that should be noted when interpreting our findings. First, the sample sizes of the 2 groups in our study were very different, so some of the differences between the premature and fullterm infants may not be apparent in the CBISQ sleep 
Table 3 Comparison of the preterm-infants group and the full-term-infants group using the CBISQ

\begin{tabular}{|c|c|c|c|c|}
\hline \multicolumn{2}{|l|}{ CBISQ Sleep measure } & \multirow{2}{*}{$\begin{array}{l}\text { Preterm infants } \\
1.0 \%\end{array}$} & \multirow{2}{*}{$\begin{array}{l}\text { Full-term infants } \\
0.0 \%\end{array}$} & \multirow{2}{*}{$\frac{P \text { value }}{-}$} \\
\hline Location of sleep & Infant crib in a separate room & & & \\
\hline & Infant crib in parents' room & $33.0 \%$ & $33.3 \%$ & 0.965 \\
\hline & In parents' bed & $64.9 \%$ & $66.6 \%$ & 0.828 \\
\hline & Infant crib in room with sibling & $1.0 \%$ & $0.0 \%$ & - \\
\hline \multirow[t]{3}{*}{ Preferred body position } & On his/her back & $52.2 \%$ & $51.0 \%$ & 0.876 \\
\hline & On his/her side & $37.7 \%$ & $31.4 \%$ & 0.397 \\
\hline & On his/her belly & $10.1 \%$ & $17.6 \%$ & 0.193 \\
\hline \multicolumn{2}{|c|}{ Nocturnal sleep duration (minutes, mean \pm SD) } & $544.87 \pm 81.93$ & $490.71 \pm 134.48$ & $0.027^{*}$ \\
\hline \multicolumn{2}{|c|}{ Nocturnal sleep-onset time ${ }^{\#}($ mean \pm SD) } & $2.61 \pm 1.31$ & $2.53 \pm 1.02$ & 0.782 \\
\hline \multirow[t]{5}{*}{ Method of falling asleep } & While feeding & $19.8 \%$ & $23.1 \%$ & 0.555 \\
\hline & Being rocked & $23.4 \%$ & $21.5 \%$ & 0.752 \\
\hline & Being held & $24.8 \%$ & $23.1 \%$ & 0.769 \\
\hline & In bed alone & $12.2 \%$ & $12.3 \%$ & 0.986 \\
\hline & In bed near parent & $19.8 \%$ & $20.0 \%$ & 0.969 \\
\hline \multicolumn{2}{|c|}{ Difficulty falling asleep ${ }^{\#}$ (mean \pm SD) } & $2.47 \pm 1.93$ & $2.16 \pm 1.71$ & 0.494 \\
\hline \multicolumn{2}{|c|}{ Number of night awakenings" (mean \pm SD) } & $2.28 \pm 0.93$ & $1.72 \pm 0.67$ & $0.014^{*}$ \\
\hline \multicolumn{2}{|c|}{ Daytime sleep duration (minutes, mean \pm SD) } & $364.07 \pm 152.1$ & $271.67 \pm 133.16$ & $0.014^{*}$ \\
\hline \multicolumn{2}{|c|}{ Subjective consideration of sleep problems ${ }^{\#}($ mean \pm SD) } & $1.53 \pm 0.69$ & $1.21 \pm 0.54$ & $0.024^{*}$ \\
\hline \multicolumn{2}{|c|}{ Time spent with mouth breathing ${ }^{\#}$ (mean $\pm S D$ ) } & $1.47 \pm 0.57$ & $1.20 \pm 0.42$ & $0.077^{+}$ \\
\hline \multicolumn{2}{|c|}{ Loud-noisy breathing ${ }^{\#}$ (mean \pm SD) } & $1.88 \pm 0.69$ & $1.44 \pm 0.51$ & $0.010^{*}$ \\
\hline \multicolumn{2}{|c|}{ Time spent with crying during night ${ }^{\#}$ (mean \pm SD) } & $1.64 \pm 0.71$ & $1.26 \pm 0.45$ & $0.003^{*}$ \\
\hline
\end{tabular}

${ }^{*} \mathrm{P}$ value $<0.05 .{ }^{+} \mathrm{P}$ value $<0.10$.

"These questions were evaluated by severity, and scored from 1 to 4 .

measurement. Second, $16.59 \%$ of our study group (premature infants) did not complete the CBISQ assessment and sleep examination when they were 6 months old, but our follow-up study had more than $70 \%$ of the initially signedup children. Third, actigraphy provides only integrated sleep data, not detailed parameters of the sleep status, so the validity testing of the CBISQ sleep measure with actigraphy was not ideal. Fourth, it is difficult to perform PSG in premature infants because of uncooperative child, night feeding and size of premature infant with too small limbs and torso for some equipments. However our premature group was large, and actigraphy and PSG data were both obtained from this large number of premature infants. But our study monitored simultaneous objective and subjective data investigating sleep problems of the premature.

Using this reliable and validated tool, the CBISQ, longitudinal studies surveying premature infants using sleep measurement and mental development every 3 months from birth can be designed to address the issue of delayed development in premature infants and how this correlates with sleep-breathing disorders or poor nocturnal sleep quality. Use of the CBISQ may help clinicians follow the evolution of sleep problems overtime and schedule sleep studies when needed.

\section{Conclusion}

Infancy sleep maturation may impact the maturation of the central nervous system, overall functioning, and future cognitive, motor, and temperament development. Premature infants have more sleep problems than full-term infants, including the known risk of abnormal breathing during sleep, which has been well demonstrated already with the BISQ-Chinese (CBISQ).The longitudinal studies surveying premature infants using sleep measurement and mental development every 3 months from birth can be designed to address the issue of delayed development in premature infants and how this correlates with sleepbreathing disorders or poor nocturnal sleep quality.

\section{Additional file}

Additional file 1: Brief Infant Sleep Questionnaire-Chinese version (CBISQ). The CBISQ is derived from the Brief Infant Sleep Questionnaire (BISQ) [19] of Avi Sadeh. We translated the BISQ from English to Chinese.

\section{Abbreviations}

BISQ: Brief infant sleep questionnaire; CBISQ: Brief infant sleep questionnaire-Chinese version; PSG: Polysomnography; AHI: Apnea-Hypopnea Index; PICU: Premature intensive care unit. 


\section{Competing interests}

The authors declare that they have no competing interests.

\section{Authors' contributions}

Y-SH: designed and organized the study, collected and conducted the data analysis and drafted the manuscript. CG: scientific advisor, co-designed the study, supervised the research process and strictly revised the manuscript. M-CK: participated in the study design and data analysis, and rechecked the data-related issues. TP: participated in study design and revision of the manuscript. J-FH: participated in the data collection. All authors read and approved the final manuscript.

\section{Acknowledgements}

This study is part of the project of PhD candidate Yu-Shu Huang at Lisbon University, entitled "Longitudinal study of premature infants from birth till 18 months of age evaluating presence and evolution of anatomic risk-factors for sleep-disordered-breathing". We thank Dr Avi Sadeh for allowing us to use the BISQ questionnaire.

\section{Disclosure statement}

This research was supported by a grant from the National Science Council, Taiwan (NSC 101-2314 - B - 182A - 072 - MY3) and the fund of Chang Gung Memorial Hospital (CRRPG5C0171). We have indicated no financial conflicts of interest.

\section{Author details}

${ }^{1}$ Sleep Center and Child Psychiatry Department, Chang Gung Memorial Hospital and Chang Gung University, Taoyuan, Taiwan. ${ }^{2}$ Clinical Neurosciences Department, Faculdade Medicina Lisboa, University of Lisbon, Lisbon, Portugal. ${ }^{3}$ Division of Pediatric Neonatology, Department of Pediatrics, Chang Gung Memorial Hospital and Chang Gung University, Taoyuan, Taiwan. ${ }^{4}$ Stanford University Sleep Medicine Division, 450 Broadway Street, MC 5704, Redwood City CA 94063, Stanford, USA.

Received: 23 April 2014 Accepted: 27 November 2014 Published online: 16 December 2014

\section{References}

1. Carskadon MA, Dement WC: Normal human sleep: an overview. In Principles and Practice of Sleep Medicine. 4th edition. Edited by Kryger $\mathrm{MH}$, Roth T, Dement WC. Philadelphia: Elsevier Saunders; 2005:13-23.

2. Thoman EB: Sleeping and waking states in infants: a functional perspective. Neurosci Biobehav Rev 1990, 14:93-107.

3. Grigg-Damberger M, Gozal D, Marcus CL, Quan SF, Rosen CL, Chervin RD, Wise M, Picchietti DL, Sheldon SH, Iber C: The visual scoring of sleep and arousal in infants and children. J Clin Sleep Med 2007, 3:201-240.

4. Parmelee $\mathrm{AH}$, Stern E: Development of states in infants. In Sleep and the Maturing Nervous System. Edited by Clemente CD, Purpura DP, Mayer FE. New Yoek: Academic Press; 1972:199-228.

5. Coons S, Guilleminault C: Development of sleep-wake patterns and non-rapid eye movement sleep stages during the first six months of life in normal infants. Pediatrics 1982, 69:793-798.

6. Anders TF, Keener M: Developmental course of nighttime sleep-wake patterns in full-term and premature infants during the first year of life. I. Sleep 1985, 8:173-192.

7. Iber C, Ancoli-Israel S, Chesson A, Quan SF: The AASM Manual for the Scoring of Sleep and Associated Events: Rules, Terminology and Technical Specifications. Westchester, IL: American Academy of Sleep Medicine; 2007.

8. Beckwith $\mathrm{L}$, Parmalee $\mathrm{AH}$ : EEG patterns of preterm infants, home environment, and later IQ. Child Dev 1986, 57:777-789.

9. Curzi-Dascalova L, Peirano P, Morel-Kahn F: Development of sleep states in normal premature and full-term newborns. Dev Psychobio/ 1988, 21:431-444.

10. Kinney HC, Brody BA, Kloman AS, Gilles FH: Sequence of central nervous system myelination in human infancy. II. patterns of myelination in autopsied infants. J Neuropathol Exp Neurol 1988, 47:217-234

11. Rivkees SA: Developing circadian rhythmicity in infants. Pediatrics 2003 , 112:373-381.

12. Panda S, Hogenesch JB, Kay SA: Circadian rhythms from flies to human. Nature 2002, 417:329-335.

13. Upton CJ, Milner AD, Stokes GM: Upper airway patency during apnoea of prematurity. Arch Dis Child 1992, 67:419-424.
14. Idiong N, Lemke RP, Lin YJ, Kwiatkowski K, Cates DB, Rigatto H: Airway closure during mixed apnoeas in preterm infants: is respiratory effort necessary. J Pediatr 1998, 133:509-512.

15. Finer NN, Barrington KJ, Hayes BJ, Hugh A: Obstructive, mixed and central apnoea in the neonate: physiologic correlates. J Pediatr 1992, 121:943-950.

16. Korobkin R, Guilleminault C: Neurologic abnormalities in near miss for sudden infant death syndrome infants. Pediatrics 1979, 64:369-374.

17. Korner AF, Guilleminault C, van den Hoed J, Baldwin RB: Reduction of sleep apnea and bradycardia in pre-term infants on oscillating waterbeds: a controlled polygraphic study. Pediatrics 1978, 61:528-533.

18. Huang YS, Guilleminault C: Pediatric obstructive sleep apnea and the critical role of oral-facial growth: evidences. Front Neurol 2013, 3:184. doi:10.3389/fneur.2012.00184.

19. Sadeh A: A brief screening questionnaire for infant sleep problems: validation and findings for an internet sample. Pediatrics 2004, 113:e570-e577.

20. Bernal JF: Night waking in infants during the first 14 months. Dev Med Child Neurol 1973, 15:760-769.

21. 21 Sharma PB, Baroody F, Gozal D, Lester LA Obstructive sleep apnea in the formerly preterm infant: an overlooked diagnosis, Fneuro. doi:10.3389/ fneur.2011.00073

22. Chang SJ, Chae Y: Obstructive sleep apnea syndrome in children: epidemiology, pathophysiology, diagnosis and sequelae. Korean $J$ Pediatr 2010, 53(10):863-871.

23. Anders TF, Halpern LF, Hua J: Sleeping through the night: a developmental perspective. Pediatrics 1992, 90:554-560.

24. Dan B, Stewart GB: A neurophysiological perspective on sleep and its maturation. Dev Med Child Neurol 2006, 48:773-779.

25. Gertner S, Greenbaum CW, Sadeh A, Dolfin Z, Sirota L, Ben-Nun Y: Sleep-wake patterns in preterm infants and 6 month's home environment: implications for early cognitive development. Early Hum Dev 2002, 68:93-102.

\section{doi:10.1186/s12887-014-0303-6}

Cite this article as: Huang et al:: Sleep and breathing in premature infants at 6 months post-natal age. BMC Pediatrics 2014 14:303.

\section{Submit your next manuscript to BioMed Central and take full advantage of:}

- Convenient online submission

- Thorough peer review

- No space constraints or color figure charges

- Immediate publication on acceptance

- Inclusion in PubMed, CAS, Scopus and Google Scholar

- Research which is freely available for redistribution

Submit your manuscript at www.biomedcentral.com/submit
C BioMed Central 